\title{
A Basic Study on a Rectangular Plane Space Sound Absorber Using Permeable Membranes
}

\author{
Kimihiro Sakagami ${ }^{1, *} \mathbb{C}$, Takeshi Okuzono ${ }^{1}\left(\mathbb{D}\right.$, Yu Somatomo $^{1}$, Kota Funahashi ${ }^{1}$ and \\ Masahiro Toyoda ${ }^{2}$ \\ 1 Environmental Acoustics Laboratory, Department of Architecture, Graduate School of Engineering, \\ Kobe University, Kobe 657-8501, Japan; okuzono@port.kobe-u.ac.jp (T.O.); \\ soma.tomo.1325@gmail.com (Y.S.); kota_tako_214@yahoo.co.jp (K.F.) \\ 2 Department of Architecture, Faculty of Environmental and Urban Engineering, Kansai University, \\ Osaka 564-8680, Japan; toyoda@kansai-u.ac.jp \\ * Correspondence: saka@kobe-u.ac.jp; Tel.: +81-78-803-6043
}

Received: 31 March 2019; Accepted: 10 April 2019; Published: 11 April 2019

\begin{abstract}
In this communication, the sound absorption characteristics of rectangular-shaped plane space sound absorbers without any backing structure using permeable membranes (PMs) are measured by reverberation room method. First, three types of PMs, in this study woven fabrics, are selected with different flow resistances and surface densities. They are prepared in the plane rectangular-shaped space absorbers of two different sizes. The measured results are discussed through comparison with the existing theoretical and measured results for absorbers of the other shapes or configurations. The present results and discussion demonstrate that the reverberation absorption coefficients of the proposed absorbers are low at low frequencies and converge to a moderately high value at high frequencies. Especially, ones with higher flow resistance than the air impedance converge to a value greater than 0.5 , which is a theoretically estimated maximum absorption coefficient of infinite single-leaf PM. This is inferred to be attributed mainly to area effect. From these results the proposed absorbers can be used effectively despite of their very simple structure. Also it is found that the proposed absorber can offer higher sound absorption than permeable membrane absorbers of other shapes or configuration. Regarding the effect of the size, the absorbers of smaller size offer higher absorption coefficients regardless of material properties of the PMs used in the experiments.
\end{abstract}

Keywords: sound absorption; permeable membrane; reverberant sound absorption coefficient; space sound absorber; rectangular plane

\section{Introduction}

Sound absorption is one of the most important techniques in architectural and building acoustics. It is used to control the reverberation time in rooms to adjust it to be suitable for the purpose of the rooms and built environment. This is of vital importance in spaces not only for musical performance [1,2] but for speech communication in any built environment, for example, public spaces such as the foyer of railway stations or airports, etc., to keep high speech intelligibility [3]. High speech intelligibility is quite important in emergency cases in buildings [4].

Not only in the emergency cases but also in daily life in any kind of buildings, sound absorption takes important role. For example, in schools it is vitally important to keep good speech communication performance, which requires suppressing reverberation as well as reducing noise level, which is also important for reducing annoyance due to noise [5-7]. Noise abatement by sound absorption is also necessary for houses in urban area to protect comfortable living environment from annoyance due to various noise including neighbour noise [8]. 
Another important role of sound absorption is reducing noise level in built environments [9]. Sound absorbers are often used also in outdoor environments to reduce noise levels, as well as, enhance the efficiency of noise barriers, etc. [10]. Recently, new materials have been used for noise barriers to improve the sound insulation performance [11]

Sound absorption materials are categorised into several types: the most conventional and widely used one is porous / fibrous materials. Traditionally, glass wool has been very widely used. However, with recent increasing demand for sustainable materials, and in an effort to avoid its deficiency in health, ecological and recyclability problems, alternative materials have been considered. Various non-fibrous and non-porous materials, which Fuchs called ALFA (Alternative Fibreless Absorbers) [12], or next-generation sound absorbers have been extensively studied since the end of last century. On the other hand, sustainable sound absorption materials made of recycled materials [13], and natural fibrous materials (for one of the most recent examples, see Kusno et al. [14]) have been extensively studied.

Among various attempts to develop sustainable sound absorptive materials, microperforated panel (MPP) [15,16] and membrane absorbers using both impermeable and permeable leaves [17] have also been extensively studied as promising substitutions for fibrous materials. Particularly the membranes are less expensive and durable, and there are various types of membrane material are now available, therefore, the authors have extensively studied different types of membrane (especially permeable membrane: PMs) absorbers [18-22]. Also, there have been various studies on fabric for curtains published so far: [23-25]. PMs are now one of the most promising sustainable sound absorption materials.

In this communication, space absorbers made of plane PM of rectangular shape are experimentally studied as a pilot study. This type of absorber has been traditionally used as a sound absorbing curtain to control the reverberation time in auditoria [2]. Woven fabrics used for curtain with drapes are used in those cases and there are studies on its sound absorptivity, e.g., [23-25]: Particularly, Pieren et al. [24] presented a comprehensive experimental and theoretical study on the absorption characteristics of woven curtain fabrics in various configurations (with and without drapes). This study gives well considered prediction method as well as physical insight into the absorption characteristics of woven fabrics. However, the range of the parameters of fabrics studied in the same study is rather limited, to lower flow resistance between 45 and $350 \mathrm{~Pa} \mathrm{~s} / \mathrm{m}$, and surface density between 0.064 and $0.13 \mathrm{~kg} / \mathrm{m}^{2}$. These are rather low in comparison to the materials used in actual buildings for acoustical purposes. For example, in membrane-structure architecture the inner leaf of the ceiling often has a flow resistance higher than $1000 \mathrm{~Pa} \mathrm{~s} / \mathrm{m}$ and surface density of at least $0.5 \mathrm{~kg} / \mathrm{m}^{2}$. Knowing that the flow resistance has an optimal value and surface density affects its performance at low frequencies [19], for building acoustical purposes, it is necessary to extend a survey to PMs of higher flow resistance and surface density.

Therefore, in this study, suspended plane rectangular-shaped woven fabrics are measured in a reverberation chamber, in order to confirm and discuss their sound absorption efficiency as a simple sound absorbing system in rooms. In the cases of curtains, they may be either flat or draped, but for conditioning room acoustics, the forms most often used are flat membranes or fabrics suspended from ceiling or other structural elements. Thus, in this study the target is focused on flat and planar PMs (woven fabrics or coated woven fabrics for building purposes). First, the typical materials of different physical properties are selected and their absorptivity is estimated by the existing theory for a PM of infinite extent [19]. Secondly, the materials are prepared for space absorber specimens of two sizes and they are measured in a reverberation chamber. Discussion will be made through the measured results in comparison with the theoretically estimated values, the measured results being for PMs of different shapes and configuration [21,22], in order to gain an insight into the sound absorption characteristics of plane square space absorber using a single-leaf PM.

The materials used in this study are PET and PTFE-coated glass fibre woven fabrics. PET woven fabric, as well as, fabrics made from other materials including natural fibres like cotton, have high recyclability [13,26]. Especially, PET is stated, according to [26], to be "completely recyclable". Besides, 
both PET and PTFE-coated glass fibre woven materials have very high durability, especially the latter is extremely strong [27]. Therefore, they have good sustainable properties. Also, as PMs' acoustical properties are characterised mainly by flow resistance [19], the results of this work are expected to be applicable to woven PMs made of any other materials.

\section{Experiment}

\subsection{Selection of Materials}

For specimens, various types of PMs (woven fabrics made of PET and glass fibre) were examined for selecting three materials. The selection was made so that the three materials encompassed a wide variety of both flow resistance and surface densities to cover the range of usual building materials. First, in order to select the material used for the experiments, the flow resistance $\left(R_{f} \mathrm{~Pa} s / \mathrm{m}\right)$ and surface density $\left(m \mathrm{~kg} / \mathrm{m}^{2}\right)$ of various PMs were measured, and the three materials in Table 1 were selected.

Table 1. Properties of materials used in the experiment.

\begin{tabular}{ccc}
\hline & Surface Density $\boldsymbol{m} \mathbf{( \mathbf { k g } / \mathbf { m } ^ { 2 } )}$ & Flow Resistance $\boldsymbol{R}_{\boldsymbol{f}} \mathbf{( P a ~ s / m )}$ \\
\hline Membrane A & 0.065 & 196 \\
\hline Membrane B & 0.120 & 462 \\
\hline Membrane C & 0.495 & 1087 \\
\hline
\end{tabular}

Regarding the measurement of these physical properties, the following method was employed. The flow resistance of the membranes was measured by conventional direct current method. The measurement was carried out with refer to ISO 9053, but due to the limitation of the compressor to generate direct air flow and the sensor, the lowest flow velocity in the measurement was $0.005 \mathrm{~m} / \mathrm{s}$. Therefore, we had to employ the extrapolation method based on JIS A 6306 (now abolished): Measurement of the differential pressure were made at various flow speeds. After having checked the linearity of the resultant differential pressure, the extrapolated value of differential pressure for the flow velocity of $0.0005 \mathrm{~m} / \mathrm{s}$ was obtained. The samples were square with side lengths of $100 \mathrm{~mm}$. In order to avoid the air leakage, clay was filled to the edges of the samples to close the possible gap between the sample and the testing tube. The measurement was very carefully made at least three times for one sample, so that the deviation could be minimized. The surface density was measured by a conventional electronic scale.

Membrane A is a light-weight and low flow resistance PET woven fabric, which is known as "completely recyclable" [26]. Membrane B is also PET woven fabric with flow resistance nearly equal to air impedance. Both are designed as a facing material for porous absorbents. Membrane $\mathrm{C}$ is a glass fibre woven fabric with PTFE coating for building use with flow resistance twice larger than the air impedance, i.e., $2 \rho_{0} c_{0}$ ( $\rho_{0}$ is the air density and $c_{0}$ is the sound speed in the air). From the previous studies [19], the optimal value of the flow resistance of PM is theoretically obtained to be $2 \rho_{0} c_{0}$. Therefore, it is expected that Membrane $C$ should offer the highest sound absorptivity.

\subsection{Estimation of the Acoustic Properties of the Selected Materials and Preliminary Test}

In order to estimate the basic acoustical properties of the selected three materials, existing theory [19] was applied to calculate its sound absorptivity. The theory [19] used is summarised below:

Consider an infinite PM shown in Figure 1, which is characterised by its surface density $m$, tension $T$ and flow resistance $R_{f}$. Using Helmholtz integrals coupled with equation of motion of membrane considering its permeability, the reflected and transmitted pressures, $p_{r}(x, z)$ and $p_{t}(x, z)$, are given as [18]:

$$
p_{r}(x, z)=\frac{\cos \theta+i \rho_{0} \omega^{2} F\left(k_{0} \sin \theta\right) \cos \theta}{\cos \theta+2 A_{M}} \exp \left[i k_{0}(\sin \theta \cdot x-\cos \theta \cdot z)\right]
$$




$$
p_{t}(x, z)=\frac{2 A_{M}-i \rho_{0} \omega^{2} F\left(k_{0} \sin \theta\right) \cos \theta}{\cos \theta+2 A_{M}} \exp \left[i k_{0}(\sin \theta \cdot x+\cos \theta \cdot z)\right]
$$

where

$$
F\left(k_{0} \sin \theta\right)=4 \pi U\left(k_{0} \sin \theta\right) /\left[2 k_{0} A_{M}+k_{0} \cos \theta-4 \pi i \rho_{0} \omega^{2} U\left(k_{0} \sin \theta\right)\right]
$$

and $U\left(k_{0} \sin \theta\right)=\left[2 \pi T\left(k_{0}^{2} \sin \theta-m \omega^{2} / T\right)\right]^{-1}, k_{0}$ the acoustic wavenumber $\left(=\omega / c_{0}, \omega\right.$ the angular frequency $)$, $A_{M}=\rho_{0} c_{0} / R_{f}$. In the following calculation the tension $T$ is neglected as its effect is known as negligible [28].

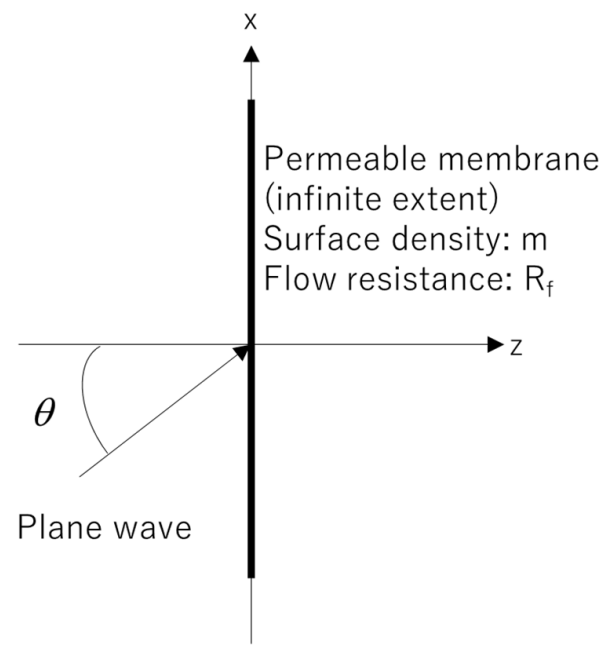

Figure 1. Geometry of the theoretical model of a PM of infinite extent with an incident plane wave of unit pressure amplitude at angle of incidence.

Since in the above solutions, Equations (1)-(3), the incident sound wave is assumed to have a unit pressure amplitude, the oblique incidence absorption and transmission coefficients, $\alpha_{\theta}$ and $\tau_{\theta}$, respectively, are obtained as:

$$
\alpha_{\theta}=1-\left|p_{r}\right|^{2}
$$

and

$$
\tau_{\theta}=\left|p_{t}\right|^{2}
$$

Therefore, the ratio of the energy dissipated in the membrane is expressed as $\alpha_{\theta}-\tau_{\theta}$ and it is proven that this value corresponds to the measured reverberation coefficients of permeable space absorbers in a reverberation chamber when averaged over the angle of incidence (usually 0 to 78 degrees for field-incidence-average) is taken. Therefore, the absorptivity of Membranes A, B and C were estimated as in Figure 2. As is seen, the membrane of higher flow resistance shows higher absorptivity. Therefore, it is expected that Membrane $C$ should give the highest absorption performance. 

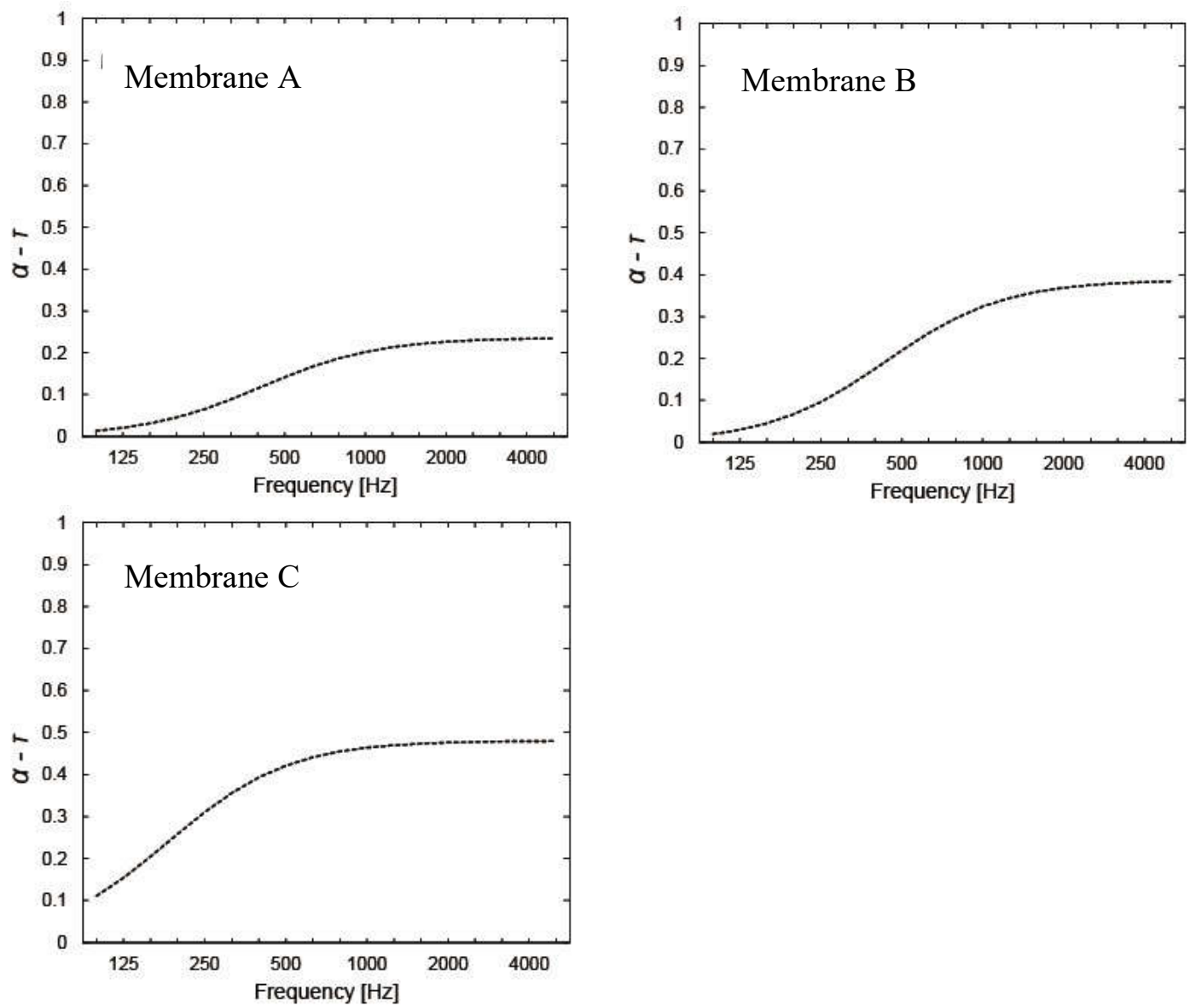

Figure 2. Sound absorptivity (the difference of absorption and transmission coefficients, indicating the ratio of dissipated energy) estimated by the existing theory [12] for Membranes A, B and C. The values are field-incidence-averaged (averaged over 0 to 78 degrees of the angle of incidence).

Also, for the reference, the normal incidence sound absorption coefficients of the membrane used in this study were measured as a preliminary test. The measured results of the normal incidence absorption coefficients of Membranes A, B and C are presented in Figure 3.

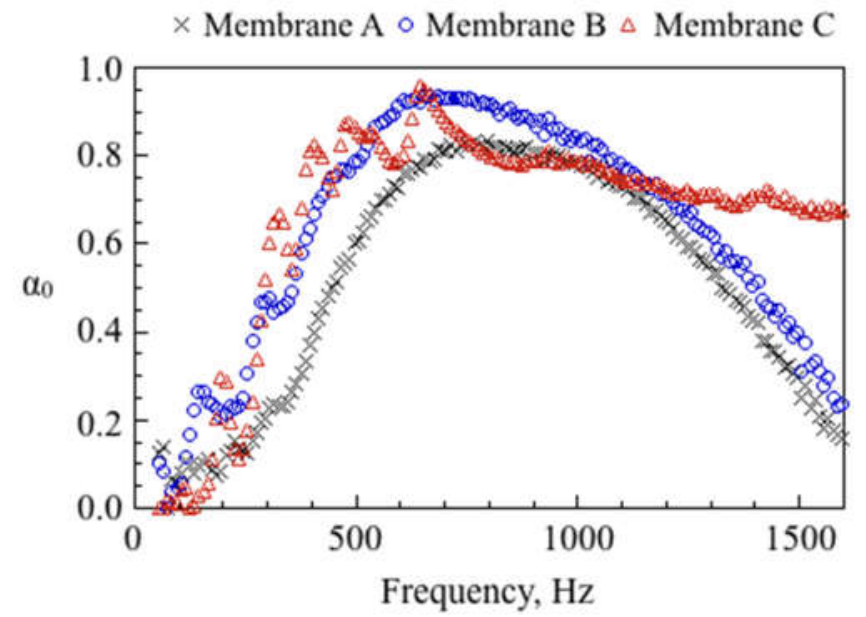

Figure 3. Normal incidence sound absorption coefficients of Membrane A (black), B (blue) and C (red) with air-back cavity of $100 \mathrm{~mm}$ depth, measured by standard impedance tube method. 
The measurement was performed by standard impedance tube method (transfer function method: ISO 10534-2, by B\&K 4206). In these measurements, the membranes are installed in a $100 \mathrm{~mm}$ diameter impedance tube with $100 \mathrm{~mm}$ air-back cavity behind them.

Due to the effect of the air-back cavity, all membranes show a peak at approximately the same frequency $(700-800 \mathrm{~Hz})$. Comparing the peak values, Membrane A gives the lowest peak, and B and C are comparable. Membrane $C$ shows small peaks below the largest peak at around $700 \mathrm{~Hz}$. These small peaks are a feature of this type of membrane: owing to the coating, PTFE-coated glass fibre woven fabrics are more stiff than other soft fabrics such as in Membranes A and B.

However, from these results it is clear that the membranes used in this study can offer a moderately high sound absorptivity when they are placed in front of rigid wall with an air gap in-between.

\subsection{Preparation of the Test Specimens}

Each of the three Membranes A to $C$ were prepared to make experimental specimens as follows: Each membrane was cut into twelve pieces, of which six were $1 \mathrm{~m}^{2}$ (square of side $1 \mathrm{~m}$ lengths) and the other six were $2 \mathrm{~m}^{2}$ ( $1 \mathrm{~m}$ high and $2 \mathrm{~m}$ wide). In this way, six pieces of two sizes of each of Membranes A to $C$ were prepared. For measurement, six specimens of each type and size of Membranes $A$ to $C$ are used. The pieces were suspended from wooden stands by plastic wires as shown in Figure 4. They were arranged randomly in the reverberation chamber to avoid as much as possible that the specimens were placed in parallel to the others.

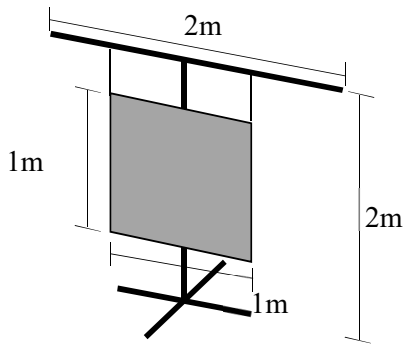

(a) Size: $1 \mathrm{~m}^{2}$

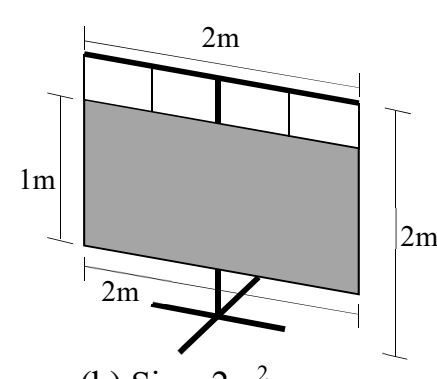

(b) Size: $2 m^{2}$

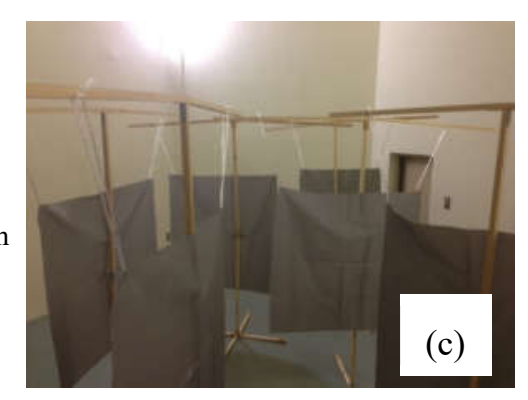

(c)

Figure 4. Outlook of the specimens. (a) $1 \mathrm{~m}^{2}$ and (b) $2 \mathrm{~m}^{2}$, with (c) a photograph of specimens of Membrane A arranged in the reverberation chamber. The same configuration was applied to Membranes A, B and C.

Considering the results of previous studies on three-dimensional MPP space sound absorbers [29,30], the equivalent sound absorption area normalized by the total area of the specimens, in which it is shown that equivalent sound absorption for $1 \mathrm{~m}^{2}$ is almost stable when the number of the specimens is changed, and can be regarded as sound absorption coefficient. Therefore, in this study, the sound absorptivity is evaluated in the same procedure, i.e., the total sound absorption was divided by the total surface area (note that in this case the area is taken for one side only, namely, $1 \mathrm{~m}^{2}$ or $2 \mathrm{~m}^{2}$ for each) resulting in the "sound absorption coefficient".

\subsection{Measurement Method}

Measurement in a reverberation chamber was performed in accordance with JIS A 1409 (ISO 354 compatible). An interrupted noise method was used in which pink noise was reproduced from a loudspeaker, and reverberation times were measured by a real-time analyser (Ono Sokki SR-5300). A single sound source was used and placed at a corner of an irregularly shaped reverberation chamber with a volume of $130 \mathrm{~m}^{3}$, and a surface area of $153 \mathrm{~m}^{2}$. Microphones were positioned at five points in the chamber and five measurements were done at each point. Reverberation sound absorption coefficient $\alpha$ was obtained by using Sabine's formula. 


\section{Results and Discussion}

Previous study [19] shows that the flow resistance of the membrane mainly affects the sound absorptivity at mid and high frequencies, whereas the surface density of the membrane mainly affects absorptivity at low frequencies. Flow resistance has an optimal value at around twice the air impedance $\rho_{0} c_{0}$, i.e., $2 \rho_{0} c_{0}$. The lightweight membrane has low sound absorptivity at low frequencies.

Figure $5 \mathrm{a}, \mathrm{b}$ show the measured results of the absorption coefficients for the cases of $1 \mathrm{~m}^{2}$ and $2 \mathrm{~m}^{2}$, respectively, and are discussed considering the above properties of PMs. Comparing Membranes $A$ and $B$, regardless to the area of the specimen, Membrane B shows higher sound absorptivity at mid and high frequencies. Considering the above previous results, this difference can be attributed to the effect of the flow resistance. The surface density of the Membrane B is about twice larger than that of $A$, both can be regarded small, therefore there is no significant difference at low frequencies below $315 \mathrm{~Hz}$.

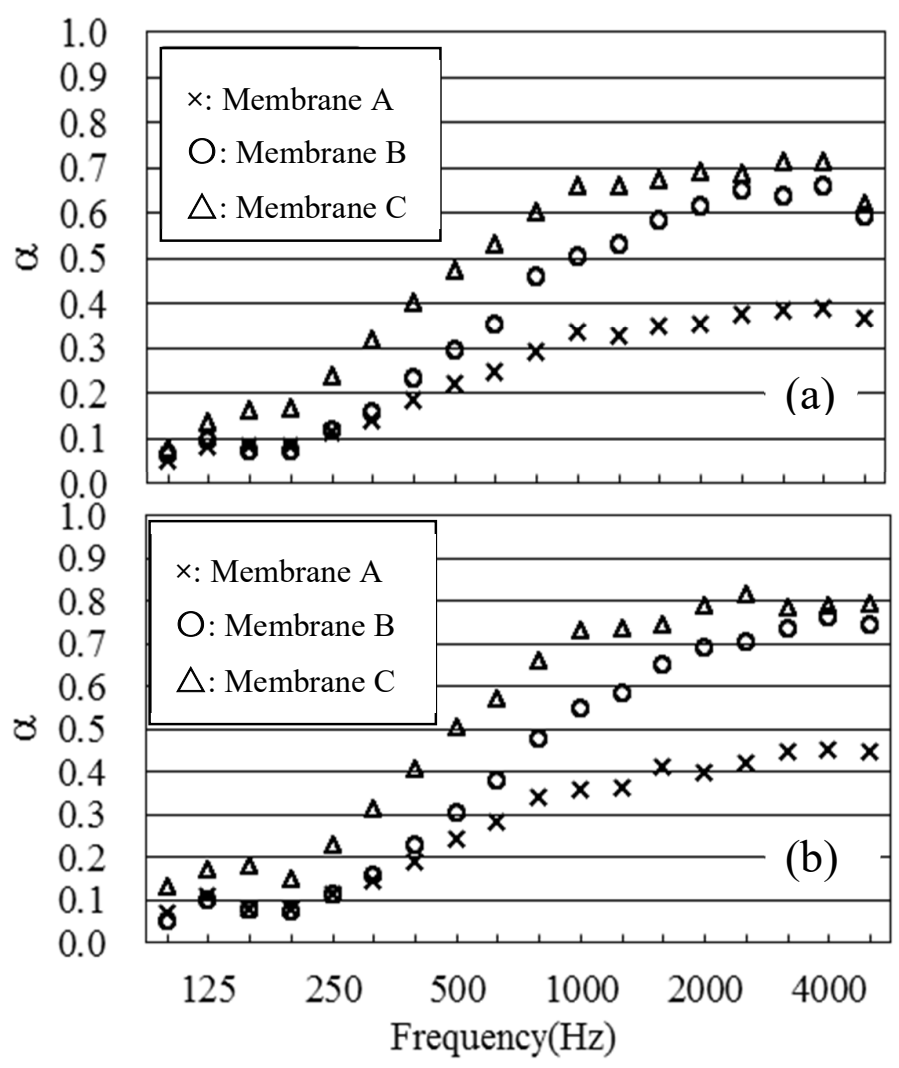

Figure 5. Comparison of the reverberation sound absorption coefficients for three types of rectangular-shaped plane space sound absorber of Membrane A, B and C. (a) Specimen size: $1 \mathrm{~m}^{2}$, (b) Specimen size: $2 \mathrm{~m}^{2}$.

Membrane C shows comparable absorptivity with Membrane B at high frequencies, however, shows higher absorptivity at low and mid frequencies. This is because the surface density of Membrane C is significantly larger than $A$ and $B$, and also its flow resistance can be considered to be close to the theoretical optimal value $2 \rho_{0} c_{0}$ [19].

Here considering that the theoretical upper limit value of the absorptivity of a single-leaf PM is 0.5 [19], the measured value in Figure 2 for Membranes B and C exceed 0.5 and converge at higher values at high frequencies. This may be attributed to the edge effect (area effect). On the other hand, Membrane A does not exceed 0.5 and converges to lower values. This is because of its low flow resistance.

Besides, comparing Figure $6 a, b$ to discuss the difference due to the area for the same membrane, in the cases of all three membranes, the specimen of smaller area, i.e., $1 \mathrm{~m}^{2}$, shows higher converging 
values at high frequencies. It is inferred that this is also attributed the fact that the area effect is more significant in the small sample cases. Another possibility of this increase may be the effect of the mutual reflection leading to the "multiple absorption" caused with other specimens or walls of the reverberation chamber.
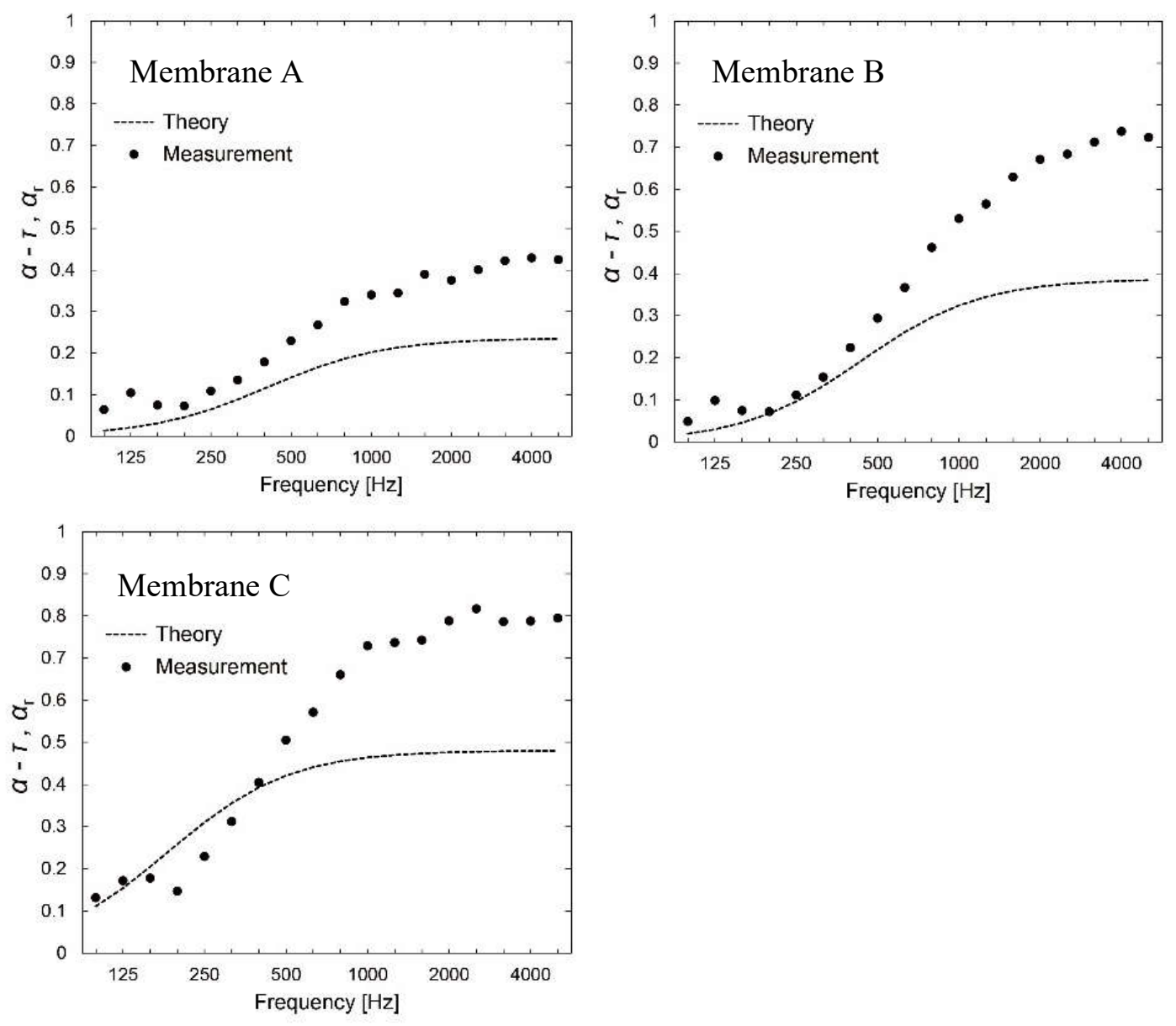

Figure 6. Comparison of the measured absorption coefficients $\left(1 \mathrm{~m}^{2}\right.$ specimens $)$ and the theoretically estimated values. From left to right: Membrane A, B and C.

Figure 6 shows examples of the comparison of the present measured results $\left(1 \mathrm{~m}^{2}\right.$ specimens of Membrane A, B and C) with the theory introduced in Section 2.2 [19]. It can easily be found that the measured results greatly exceed the theoretically estimated values.

This theory on PMs of infinite extent also showed that their maximum absorptivity mathematically becomes 0.5 . This maximum value, to which the absorptivity converges, given by the theoretical analyses in [19] is expressed by the following equation for the flow resistance $R_{f}$ and the angle of incidence $\theta$ :

$$
\operatorname{Max}(\alpha-\tau)=\frac{4 \rho c R_{f} \cos \theta}{\left(R_{f} \cos \theta+2 \rho c\right)^{2}}
$$

This equation gives 0.495 in normal incidence case $(\theta=0)$ when $R_{f}$ is $1000 \mathrm{~Pa} \mathrm{~s} / \mathrm{m}$, and it means that the absorptivity should converge to 0.5 at high frequencies if the membrane is of infinite extent. The effect of the angle of incidence is to reduce the maximum value when the angle increases, i.e., the maximum value is reached in the case of normal incidence.

Considering the above experimental results, it is confirmed that the absorptivity of a PM of finite size in a reverberation chamber exceeds it depending on its flow resistance. Also, from the above 
discussion, the rectangular-shaped plane PM space absorber can be stated to be efficiently used for controlling acoustical conditions in rooms.

Regarding the effect of the difference in the shape, Figure 7 shows an example of the comparison of the measured absorption characteristics of the plane rectangular-shaped space sound absorbers and cylindrical and rectangular three-dimensional space sound absorbers made of the same material (Membrane B) and of the same surface area $1 \mathrm{~m}^{2}$ [21]. Membrane B has moderate flow resistance and surface density, yet it shows higher sound absorption coefficient around or above 0.6 at high frequencies, whereas cylindrical and rectangular ones converge to lower values (about 0.5 ). This shows that the plane rectangular-shaped simple PM space absorber is more efficient than three-dimensional PM absorbers. The reason of this difference can be inferred that the plane rectangular-shaped has sharper edges around it and causes an area effect stronger than other three-dimensional shapes. Of course, the shape of sound absorbers should be chosen depending on architectural design, structural constriction and other considerations, so it cannot be stated which one is the best, however, the absorber proposed in this study is simple and efficient and can be one of alternatives.

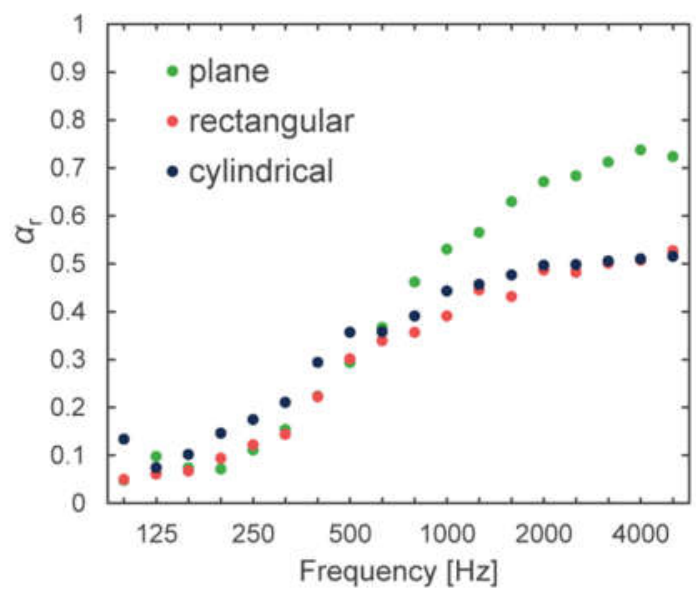

Figure 7. Comparison of the measured absorption coefficients of plane rectangular-shaped PM space sound absorber with three-dimensional (cylindrical and rectangular) PM sound absorbers [21]. All absorbers are made of the same material (Membrane B in Table 1) and have the same surface area, $1 \mathrm{~m}^{2}$.

Finally, as a reference, the sound absorption coefficient of Membranes A and B when they are backed by an air-cavity (depth $0.1 \mathrm{~m}$ on the rigid floor) is presented by dots in Figure 8 [22]. The measurements were performed also according to JIS A 1409 and in the same reverberation chamber as was used in the present study. Theoretical values by classical equivalent circuit theory are also shown. The most intriguing results will be given from the comparison with numerically simulated value by finite element method (FEM: denoted by squares) with the measured value. The simulation is performed by time-domain FEM, and, in the FEM simulation, the calculation is carried out so that the measurement in the reverberation chamber is simulated with high fidelity with modelling the entire chamber and specimen. Comparing them, the measured and FEM values are in good agreement. In this case the maximum absorption coefficient is comparable or slightly higher than that in the case of plane rectangular-shaped space absorber by Membranes A and B. As the FEM simulation takes into account of the area effect, extra high absorptivity observed in the measured results of plane rectangular space absorber is very likely to be attributed to area effect and other side effects, and will be confirmed the simulation method in [22] as a future study. 


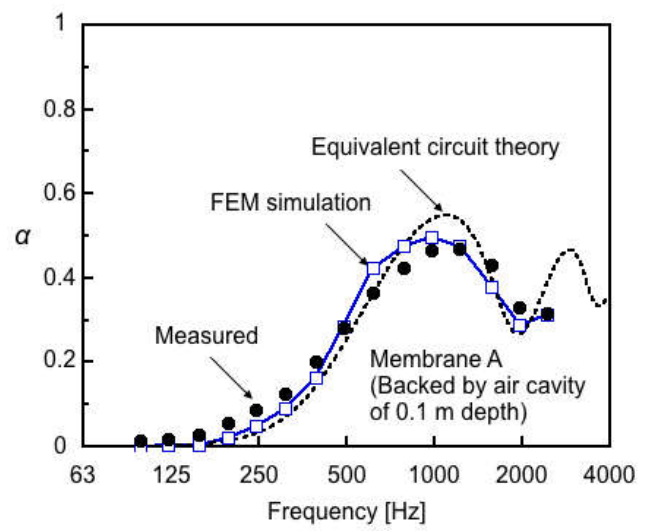

(a) Membrane A

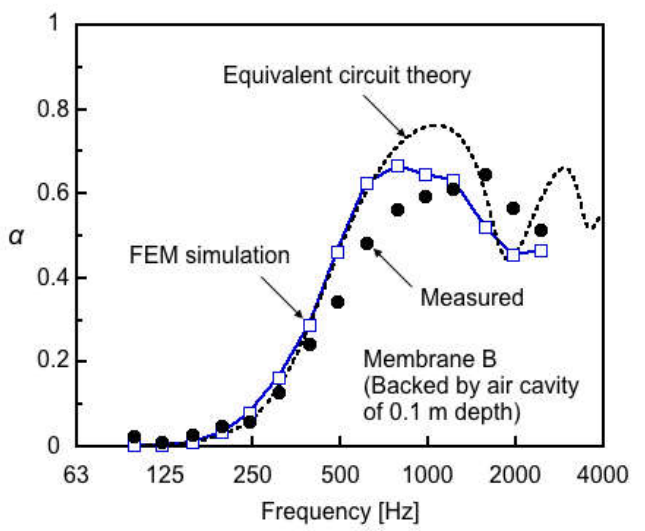

(B) Membrane B

Figure 8. Sound absorption coefficient of Membranes A and B when They are backed by an air-cavity of $0.1 \mathrm{~m}$ depth. Dots: Measured in the same reverberation chamber as used in the present study (area $6 \mathrm{~m}^{2}$ ). Squares: Numerically simulated values by FEM. Dashed line: Theoretical values by electro-acoustical equivalent circuit [22].

\section{Conclusions}

In this communication, the results are presented of the measurement of the sound absorption characteristics of rectangular-shaped plane permeable membrane space sound absorbers in a reverberation chamber. Three different combinations of flow resistance and surface density, at two sizes, were measured. The results showed that the absorbers of higher flow resistance (higher than the air impedance $\rho_{0} c_{0}$ ) offer absorption coefficients higher than the theoretical maximum value 0.5 . Regarding the difference in the size, the smaller sized specimen demonstrates greater discrepancies from the theoretical maximum value than larger specimens, i.e., specimens of smaller area shows higher value of convergence at high frequencies. The above effects can be attributed to area effect (or edge effect). Another possibility is the mutual reflection leading to "multiple absorptions" caused with other specimen or chamber walls. The cause of this feature will be the subject of future work.

Considering the results presented, permeable membranes can be used as an efficient space sound absorber to be suspended from the ceiling, etc., in rooms or spaces in a built environment. The flow resistance could be lower than the optimal value suggested by the theoretical study. This material may be used in various situations in which sound absorption is required without changing architectural design. Also, the membrane materials are durable and easy to maintain, as well as having better recyclability and eco-friendly properties [26]. They are applicable in a wide use in architectural and building acoustics. Finally, as mentioned above, the materials used in this study are of high recyclability and durability, and the proposed absorbers can be highly sustainable, however, considering the facts that the acoustical properties of PMs are mainly determined by the flow resistance [19], the results presented here have a generality and which can be applied to permeable membranes made of any other materials including natural materials. Also, this is supported by the results in the previous study: the difference in material has only small effect on the absorption characteristics, as long as the flow resistance and surface density are the same [19].

Author Contributions: Project organisation, data analyses, draft manuscript writing and editing: K.S.; measurement and experiment design and supervision, data analyses, manuscript editing: T.O. and M.T.; experiments, calculation and data analyses; Y.S. and K.F.

Funding: Research grant from Nikko Foundation, Hyogo, Japan.

Acknowledgments: The authors are indebted to Y. Fukutani and Y. Hoshino for their assistance in the selection of the materials used in this work.

Conflicts of Interest: The authors declare no conflict of interest. 


\section{References}

1. $\quad$ Kuttruff. Room Acoustics, 6th ed.; Spon Press: London, UK, 2017.

2. Maekawa, Z.; Rindel, J.H.; Lord, P. Environmental and Architectural Acoustics; Taylor and Francis: Oxford, UK, 2010.

3. Sato, H.; Morimoto, M.; Wada, M. Relationship between listening difficulty rating and objective measures in reverberant and noisy sound fields for young adults and elderly persons. J. Acoust. Soc. Am. 2012, 131, 4596-4605. [CrossRef] [PubMed]

4. Cuia, X.; Sakamoto, S.; Morimoto, M.; Suzuki, Y.; Sato, H. Effect of word familiarity on word intelligibility of four continuous words under long-path echo conditions. Appl. Acoust. 2017, 124, 38-47. [CrossRef]

5. Ascari, E.; Bianco, F.; Chetoni, M.; Fredianelli, L.; Licitra, G.; Cori, L. Assessment of the noise quality of schools rooms within the GIOCONDA project. In Proceedings of the 22nd International Congress on Sound and Vibration (ICSV 22), Florence, Italy, 12-16 July 2015.

6. Chetoni, M.; Ascari, E.; Bianco, F.; Fredianelli, L.; Licitra, G.; Cori, L. Global noise score indicator for classroom evaluation of acoustic performance in LIFE GIOCONDA project. Noise Mapp. 2016, 3, 157-171. [CrossRef]

7. Minichilli, F.; Gorini, F.; Ascari, E.; Bianchi, F.; Coi, A.; Fredianelli, L.; Licitra, G.; Manzoli, F.; Mezzasalma, L.; Cori, L. Annoyance judgment and measurements of environmental noise; A focus on Italian secondary schools. Int. J. Environ. Res. Public Health 2018, 15, 208. [CrossRef]

8. Cassina, L.; Fredianelli, L.; Menichini, I.; Chiari, C.; Licitra, G. Audio-visual preferences and tranquillity ratings in urban areas. Environments 2018, 5, 1. [CrossRef]

9. Hothersall, D.C.; Horoshenkov, K.V.; Mercy, S.E. Numerical modelling of the sound field near a tall building with balconies near a road. J. Sound Vib. 1996, 198, 507-515. [CrossRef]

10. Fujiwara, K. Novel Approach to Noise Barriers. J. INCE Jpn. 1999, 3, 131-136. (In Japanese)

11. Fredianelli, L.; Del Pizzo, A.; Licitra, G. Recent developments in sonic crystals as barriers for road traffic noise mitigation. Environments 2019, 6, 16. [CrossRef]

12. Fuchs, H.V. Alternative fibreglass absorbers-New tools and materials for noise control and acoustic comfort. Acust./Acta Acust. 2001, 87, 414-422.

13. Arenas, J.P.; Crocker, M.J. Recent trend in porous sound-absorbing materials. Sound Vib. 2010, 44, 12-17.

14. Kusno, A.; Sakagami, K.; Okuzono, T.; Toyoda, M.; Otsuru, T.; Mulyadi, R.; Kamil, K. A pilot study on the sound absorption characteristics of chicken feathers as an alternative sustainable acoustical material. Sustainability 2019, 11, 1476. [CrossRef]

15. Maa, D.-Y. Theory and design of microperforated panel sound-absorbing construction. Sci. Sin. 1975, 18, $55-71$.

16. Herrin, D.; Liu, J.; Seybert, A. Properties and applications of microperforated panels. Sound Vib. 2011, 45, 6-9.

17. Ingard, K.U. Notes on Sound Absorption Technology; INCE: New York, NY, USA, 1996.

18. Takahashi, D.; Sakagami, K.; Morimoto, M. Acoustic properties of permeable membranes. J. Acoust. Soc. Am. 1996, 99, 3003-3009. [CrossRef]

19. Sakagami, K.; Kiyama, M.; Morimoto, M.; Takahashi, D. Detailed analysis of the acoustic properties of a permeable membrane. Appl. Acoust. 1998, 54, 93-111. [CrossRef]

20. Sakagami, K.; Uyama, T.; Morimoto, M.; Kiyama, M. Prediction of the reverberation absorption coefficient of finite-size membrane absorbers. Appl. Acoust. 2005, 66, 653-668. [CrossRef]

21. Sakagami, K.; Funahashi, K.; Somatomo, Y.; Okuzono, T.; Nishikawa, C.; Toyoda, M. An experimental study on the absorption characteristics of a three-dimensional permeable membrane space sound absorber. Noise Control Eng. J. 2015, 63, 300-307. [CrossRef]

22. Okuzono, T.; Shimizu, N.; Sakagami, K. Predicting absorption characteristics of single-leaf permeable membrane absorbers using finite element method in a time domain. Appl. Acoust. 2019, 151, 172-182. [CrossRef]

23. Peuitz, V.M.A. Sound absorption of curtains. J. Acoust. Soc. Am. 1970, 48 Pt 1, 80. [CrossRef]

24. Pieren, R.; Schaeffer, B.; Schoenwald, S.; Eggenschwiler, K. Sound absorption of textile curtains-Theoretical models and validations by experiments and simulations. Text. Res. J. 2018, 88, 36-48. [CrossRef]

25. Zenong, C.; Xianhui, L.; Xiaoling, G.; Tuo, X.; Bin, Z.; Xiwen, G.; Fang, W. An empirical model for the prediction of the sound absrption of folded curtains. In Proceedings of the International Congress on Sound and Vibration 25, Hiroshima, Japan, 8-12 July 2018. 
26. Adams, T. Sound Materials: A Compendium of Sound Absorbing Materials for Architecture and Design; Frame Pub.: New York, NY, USA, 2017.

27. Fabrasorb Acoustical Membrane Materials. Available online: https://www.sheerfill.com/product-solutions/ fabrasorb (accessed on 5 April 2019).

28. Sakagami, K.; Morimoto, M.; Takahashi, D. A note on the acoustic reflection of an infinite membrane. Acustica 1994, 80, 569-572.

29. Oshitani, T.; Yairi, Y.; Toyoda, E.; Morimoto, M. An experimental study on a cylindrical microperforated panel space sound absorber. Noise Control Eng. J. 2012, 60, 22-28.

30. Sakagami, K.; Yairi, M.; Toyoda, M.; Toyoda, E. An experimental study on the sound absorption of three dimensional MPP space sound absorbers: Rectangular MPP space sound absorber (RMSA). Acoust. Aust. 2013, 41, 156-159.

(C) 2019 by the authors. Licensee MDPI, Basel, Switzerland. This article is an open access article distributed under the terms and conditions of the Creative Commons Attribution (CC BY) license (http://creativecommons.org/licenses/by/4.0/). 